\title{
0 gesto autoral em favor de uma outra ética no Design
}

\section{Authoral gesture for another ethics in Design}

\author{
Mariana Borges dos Santos ${ }^{[1]}$, Mariana Piccoli $^{[2]}$ (orient.), \\ Ana Paula Freitas Margarites ${ }^{[3]}$ (orient.)
}

\begin{abstract}
Resumo: Este artigo é um recorte do trabalho de conclusão do curso de Bacharelado em Design, intitulado "Curadoria de Si: ensaio cartográfico sobre a autoria no processos de formação de uma designer" e trata de uma revisão bibliográfica acerca da autoria nos campos da arte, da literatura, da filosofia e do design. Esta escrita foi motivada pelas inquietações acerca da minha relação com o design e buscou compreender a autoria enquanto um modo de estar que fosse variável, processual, sintonizado com a potencialização dos modos de vida (singulares e coletivos) e orientado por ética e estética.
\end{abstract}

Palavras-chave: Autoria; Arte; Design; Ética; Estética.

Abstract: This article is a cut-off from the Design Bachelor course's completion work, entitled "Self Curatorship: cartographic essay about the authorship in the formation processes of a designer" and deals with a bibliographical review about authorship in the fields of art, literature, philosophy and design. This writing was motivated by concerns about my relationship with design and sought to understand authorship as a way of being that was variable, procedural, attuned to the empowerment of lifestyles (singular and collective) and guided by ethics and aesthetics.

Keywords: Design; Autorship; Cartography; Ethics.

[1] Graduação em Design, IFSUL.mariamarianaborges@gmail.com

[2] Doutorado em Ciência e Engenharia de Materiais (em andamento), UFPEL. marianap.piccoli@gmail.com

[3] Doutorado em Educação (em andamento),

UFPEL.anamargarites@gmail.com 


\section{INTRODUÇÃo}

Lembro que, durante a graduação, nas aulas de Teoria e Crítica, discutíamos calorosamente a dicotomia entre design aplicado e autoral, buscando encontrar afirmativas que respondessem às escalas de valor estabelecidas por meio de um pensamento dialético, opositor. E, na maioria das vezes em que essa discussão se instaurava, a sala se transformava em um embate polarizado entre duas figuras ficcionais de designer possíveis: de um lado o designer dos mercados (da comunicação, da publicidade, do consumo); de outro o designer autor, artista, indivíduo livre para auto expressão. O mau e o bom. O vilão e o herói. Bastava escolher um lado no debate e defendê-lo até esgotarem os argumentos ou o tempo do período.

Das aulas de Teoria e Crítica pra cá, muitos e novos pontos de vista foram agregados nessa construção e hoje já consigo compreender que apenas duas possibilidades são insuficientes para dar conta dessa discussão. Então escolho afirmar aqui as proximidades, ao invés das distâncias entre os supostos lados. E multiplicá-los. Expandi-los.

Por isso, digo que a autoria está aqui como aposta. Mais uma aposta nessa discussão batida e rebatida no interior do campo do design e fora dele. E, definitivamente, não a faço para afirmar um determinado juízo de valor entre os modos de ser designer e sim para engrossar o coro que busca ampliar, movimentar e misturar esses modos.

Abordar a discussão sobre a autoria implicou em retomar os pontos principais da articulação discursiva que já foi construída até o presente, nos campos da arte (MALYSSE, 2009; BASBAUM, 1996; DUCHAMP, 1975), da filosofia (FOUCAULT, 2009 [1969]) e do texto literário (BARTHES, 2004 [1968]) e, a partir daí, buscar algumas relações com o campo do design (ROCK, 1996; LUPTON, 1998; POYNOR, 2010; MEGGS, 2009; MCCARTHY, 2013). 


\section{AUTORIA NO CAMPO DA ARTE}

A questão da autoria se desdobra, necessariamente, em questões mais específicas que serão próprias de cada campo em que esta se insere. Dos possíveis aspectos do artista enquanto autor, um me interessa mais que outros, e este foi colocado por Marcel Duchamp logo no início do século XX. Em resumo, é sobre a contribuição de Duchamp que trata este capítulo da história da arte.

De toda a história da arte, faço um recorte breve e recente, necessário apenas para a compreensão desse ponto sobre autoria, que é onde quero chegar. Antes disso, preciso mencionar um tempo em que a arte esteve comprometida estritamente com o belo, com a forma. As belas artes já foram sinônimo de um conjunto de técnicas executadas exaustivamente em busca da mais perfeita representação da realidade, exemplo disso é a arte renascentista (BARROS, 2008). E dessa concepção de arte, muitas descobertas acerca da imagem foram herdadas: harmonias cromáticas, proporções áureas, perspectivas, estudos de representação de luz e sombra, dentre muitos outros recursos desenvolvidos para fins de representação e dos quais não me desfaço. Estes recursos, inclusive, constituem parte da base teórica do design, vale lembrar.

Isto posto, pulemos para a modernidade, momento que favoreceu para que muitos dos movimentos e correntes artísticas fizessem afirmar a possibilidade de autonomia das obras em relação à representação de algo que preexistisse a elas.

A pintura, por exemplo, libertava-se simultaneamente da obrigação de representar algo externo a ela mesma e da obrigação de esconder do observador da obra as marcas que denunciam a própria natureza do objeto contemplado como uma livre criação artística (BARROS, 2008, p.2).

Exemplo disso foi o movimento cubista, do qual participaram Picasso, Braque e o próprio Duchamp (MALYSSE, 2009). Nesse movimento, os artistas experimentaram para além da própria técnica, inserindo colagens de materiais diversos que 
interagiam com a pintura. Eles expandiram as possibilidades da técnica já reconhecida que era a pintura. E, com isso, colocavam novas questões para o campo, ainda que questões formais. Logo no início do século, em 1915, Duchamp começou a primeira peça da nova fase de sua obra. O Grande Vidro foi oficialmente acabado em 1925, quando um acidente rachou a peça e esta rachadura foi assimilada por ele como parte da obra. A escolha de manter algo que surgiu como um erro, foi uma afirmação do acaso como parte do processo de criação. A partir disso, ele elaborou que o artista não tem controle exclusivo de todo o processo de materialização de um conceito, uma intenção. Existem mais fatores que participam do ato de criação.

A partir de 1913, ele começa a criar uma série de objetos conhecidos como ready-mades. Estes objetos não eram esculturas esculpidas artesanalmente como criação artística, como a escultura podia ser concebida até então. Estes objetos eram corriqueiros, existentes no mundo comum dos objetos, fabricados industrialmente, não feitos por ele (o autor). Ele escolhia objetos e os recolocava assinados, o que Ihe atribuía a autoria no contexto de arte. Era a escolha, o deslocamento que se constituía como obra. Tratava-se de uma ideia. De um conceito. Estes objetos geraram tantos questionamentos sobre a própria arte e seus correlativos, que foram tidos como precursores de uma expansão do campo da arte, discutida nos anos 60, quando começaram a surgir as instalações, a arte participativa e a arte conceitual. No texto intitulado $O$ Ato Criador, Marcel Duchamp elabora as questões sobre a autoria compartilhada entre o artista e o público e nomeia um conceito importante: o coeficiente artístico.

C (...) na cadeia de reações que acompanham o ato criador falta um elo. Esta falha que representa a inabilidade do artista em expressar integralmente a sua intenção; esta diferença entre o que quis realizar e o que na verdade realizou é o "coeficiente artístico" pessoal contido na sua obra de arte. Em outras palavras, o "coeficiente artístico" pessoal é como que uma relação aritmética entre o que permanece inexpresso embora intencionado, e o que é expresso não-intencionalmente. Durante o ato criativo, o 
artista passa da intenção à realização, através de uma série de ações em cadeia que são totalmente subjetivas. A luta para realizar a sua obra leva o artista a passar por uma longa série de esforços, dores, satisfações, recusas e decisões, que não podem nem devem ser totalmente conscientes, pelo menos do ponto de vista estético. $O$ resultado desta luta é a diferença entre a intenção e a realização, diferença da qual o artista nem sempre é consciente. Um corte, uma parte que falta no seu processo criativo, representa a impossibilidade do artista enxergar completamente a sua intenção. Esta diferença entre o projeto inicial e a realização final é o próprio coeficiente da arte (DUCHAMP, 1975, p.34).

Aqui o foco é direcionado ao leitor, ou fruidor no caso da obra de arte. É ele quem irá completar o processo de criação da obra. Ou mesmo recriá-la a partir das conexões que traça na sua relação com o mundo. Questões não apenas formais, mas também e principalmente conceituais. É a obra se abrindo para o outro.

Foi Duchamp quem colocou a frase que justifica este capítulo na discussão sobre autoria: "são os espectadores que fazem os quadros" (MARCADÉ, 2008, p.248 apud MALYSSE, 2009, p.52). Com essa sentença, ele prenunciou, no campo da arte, a discussão que seria elaborada por Foucault e Barthes e que veio a afirmar este ponto de vista. Autocrítico no que tange a arte e seu campo e emancipador para o espectador, que agora tende a abandonar a função de contemplador passivo das obras de arte.

Marcel Duchamp se dirigia aos espectadores com ideias, conceitos a serem elaborados em conjunto com eles, e desses conceitos não era excluída a contradição. Ele afirmou a escolha como ato artístico. $\mathrm{O}$ artista pode não se deter ao trabalho artesanal de criação das obras, ele pode escolher objetos e escolher onde inserir os objetos. Tais escolhas materializavam em gesto, as intenções e os conceitos que o artista desejava evocar.

Se a obra de arte é um ponto de vista sobre o mundo, pedindo um outro ponto de vista, o do público, que deve ler e interpretar os gestos dos artistas e as suas intenções, estamos propondo aqui uma pragmática da 
arte que seja uma estética pelo gesto, em que o artista, em vez de esconder seus gestos criativos, transformaos na gênese da obra (MALYSSE, 2009, p.52).

Para Gell "as obras de arte nos fazem imaginar as diferentes intenções ligadas às suas produções e nos obrigam a representá-las com intenções próprias" (1998, p.148). Em vez de pensar a arte em termos de beleza, deveríamos, segundo ele, concebê-la em termos de intenções, sejam imaginárias ou reais ( MALYSSE, 2009, p.52).

Além desse efeito que a obra tem no espectador para que se complete enquanto criação, Basbaum traz outro efeito fundamental da obra: o de [re]criar o seu autor.

CC No sistema de funcionamento característico da arte contemporânea, vemos que a função-autor só pode legitimar-se a partir de uma identidade processual, que incorpore o efeito da obra também sobre si, num caminho aberto de autodiferenciação permanente (BASBAUM, 1996, p.5; grifo nosso).

(C O sujeito criador dissolve-se num "devir-imperceptível" como parte da atividade desse despojar-se das determinações apriorísticas para relocalizar-se nos contornos de um outro espaço, relacional; evita-se o "aspecto (...) pelo qual a inteligência vem sempre antes, pelo qual o todo já se encontra presente e a lei já é conhecida antes daquilo que vai aplicá-la: (...) em que nada mais se faz do que reencontrar o que já estava dado de antemão e de onde só se tiram as coisas que aí tinham sido colocadas" (BASBAUM, 1996, p.5).

Continuando esta colocação de Basbaum (1996), é possível pensar a obra enquanto uma sequencialidade de processos de criação e formação, em que as peças produzam efeitos em ambos, leitor e autor. O autor cria uma peça e é recriado por ela, enquanto artista. Este processo de diferenciação permanente muito se conecta com a ideia de coeficiente artístico, retomando Duchamp, já que a obra tem a potência de 
produzir novos sentidos a cada encontro com o outro, e algo que não foi intencionado pelo autor no momento da criação pode surgir como um novo afetamento que a obra lhe produz. $O$ autor também é leitor da própria obra. Nesse sentido, de descentrar o autor em função do leitor, a arte prenuncia um movimento de mesmo sentido que aconteceria no campo do texto literário.

\section{A FIGURA DO AUTOR NO TEXTO LITERÁRIO}

A questão da autoria é anterior à discussão sobre autoria no design, conforme vimos no contexto da arte. As elaborações teóricas sobre o design autoral, que datam da década de 1990, propunham retomar tais aspectos anteriores para compreender o funcionamento desse conceito, dentro e fora do campo. No ensaio $O$ designer enquanto autor ${ }^{[3]}$, Michael Rock fez um apanhado sobre a definição de autor e retomou a discussão localizada na França, datada do fim da década de 1960, pelo viés da literatura (BARTHES[4], 1968) e da análise do discurso (FOUCAULT[5], 2009). Proponho remontar essa digressão feita por Rock em 1996 antes de focar nas implicações da autoria no campo do design.

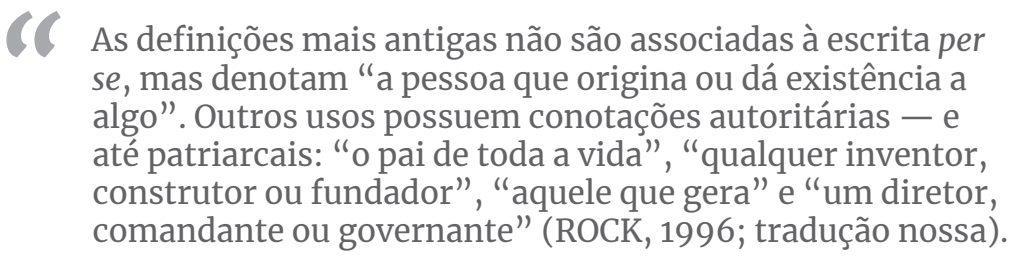

Embora a literatura, por si só, não contenha a origem das definições sobre autoria, foi a partir da sua crítica que surgiu a primeira separação entre autor e texto, no ensaio divisor de águas The intentional Fallacy (WIMSATT, BEARDSLEY, 1946, apud ROCK, 1996). Este ensaio foi um dos primeiros a reflexionar sobre tais relações, alegando que o leitor jamais poderia conhecer um autor pelos seus textos (ROCK, 1996). Mais de vinte anos após este ensaio é que Roland Barthes, de
[3] Artigo publicado por Michael Rock em 1996, na revista norte americana Eye Magazine: The Designer as Author.

[4] Publicação original: Paris: Manteia, 1968.

[5] Publicação original: Conferência: O que é um autor?, Bulletin de la Société Française de Philosophie, $63^{\circ}$ ano, n.23, JulhoSetembro de 1969, ps. 73104. (Société Française de Philosophie, 22 de fevereiro de 1969; debate com M. de Gandillac, L, Goldmann, J. Lacan, J, d'Ormesson, J. Ullmo, J. Wahl.) 
forma radical e sucinta, publicou A Morte do Autor, na Paris de 1968. O francês pontuou, com esse texto, o nascimento da teoria da crítica que suscitava uma ruptura significativa na figura do autor (ROCK, 1996).

Barthes derrubava a autoridade do autor, que na modernidade era tido como figura central do discurso, em favor do surgimento do leitor. E, considerando o momento revolucionário que Paris vivia em 1968, com estudantes e trabalhadores organizando uma greve geral, o ensaio alcançou ressonância real nos leitores - ou seja, nas massas (ROCK, 1996). Era uma proposição emancipadora do que seria o leitor, já que o autor figuraria como alguém à disposição da escrita, importando menos a sua intencionalidade do que a significação feita pelo leitor. Nas minhas palavras: o autor como um mediador de sentido. Nas palavras dele:

Assim se revela o ser total da escrita: um texto é feito de escritas múltiplas, saídas de várias culturas e que entram umas com as outras em diálogo, em paródia, em contestação; mas há um lugar em que essa multiplicidade se reúne, e esse lugar não é o autor, como se tem dito até aqui, é o leitor: o leitor é o espaço exato em que se inscrevem, sem que nenhuma se perca, todas as citações de que uma escrita é feita; a unidade de um texto não está na sua origem, mas no seu destino, mas este destino já não pode ser pessoal: o leitor é um homem sem história, sem biografia, sem psicologia; é apenas esse alguém que tem reunidos num mesmo campo todos os traços que constituem o escrito. (...) sabemos que, para devolver à escrita o seu devir, é preciso inverter o seu mito: o nascimento do leitor tem de pagar-se com a morte do autor (BARTHES, 2004, p. 5).

Em uma conferência, intitulada pela pergunta retórica $O$ que é um Autor?, Michael Foucault apresentou, em 1969, o começo de um trabalho que propunha caminhos de análise que poderiam vir a indicar uma tipologia do discurso, para além de uma classificação das suas características gramaticais, estruturais ou de seus objetos, mas que buscasse entender traços do que seriam as funções do autor na complexidade de suas operações. Em resposta à morte do autor, colocada por Barthes no ano anterior, ele propôs continuidade à discussão: 
Mas não basta, evidentemente, repetir como afirmação vazia que o autor desapareceu. Igualmente, não basta repetir perpetuamente que Deus e o homem estão mortos de uma morte conjunta. O que seria preciso fazer é localizar o espaço assim deixado vago pela desaparição do autor, seguir atentamente a repartição das lacunas e das falhas e espreitar os locais, as funções livres que essa desaparição faz aparecer (FOUCAULT, 2009, p.271).

Ele demonstrava, neste ensaio, o longo percurso que a figura do autor vinha fazendo desde a antiguidade, em diferentes tipos de escrita. Segundo ele, teria havido um tempo em que o distanciamento temporal dos escritos bastasse para conferir-Ihes credibilidade, dispensando assim um autor. Enquanto outros textos, classificados de certa forma como científicos, exigiam um ser de credibilidade que os validasse. Assim como a escrita literária, a partir do momento em que foi tida como possibilidade de transgressão, também passou a exigir alguém, ou alguma figura a quem a crítica pudesse responsabilizar. Ele faz uma separação importante entre o nome do autor e o nome próprio que, também é o nome do autor.

(C Um nome de autor não é simplesmente um elemento em um discurso (que pode ser sujeito ou complemento, que pode ser substituído por um pronome etc.); ele exerce um certo papel em relação ao discurso: assegura uma função classificatória; tal nome permite reagrupar um certo número de textos, delimitá-los, deles excluir alguns, opô-los a outros (FOUCAULT, 2009, p.273).

Ele distingue a palavra dita por um autor das palavras cotidianas como "uma palavra que deve ser recebida de uma certa maneira e que deve, em uma dada cultura, receber um certo status" (2009, p.274) e exemplifica:

Uma carta particular pode ter um signatário, ela não tem autor; um contrato pode ter um fiador, ele não tem autor. Um texto anônimo que se lê na rua em uma parede terá um redator, não terá um autor. A função-autor é, portanto, característica do modo de existência, de circulação e de funcionamento de certos discursos no interior de uma sociedade (FOUCAULT, 2009, p.274; grifo nosso). 
Tendo exposto algumas características da função do autor, ele resume autoria como "uma série de operações específicas e complexas; ela não remete pura e simplesmente a um indivíduo real, ela pode dar lugar simultaneamente a vários egos, a varias posições-sujeito que classes diferentes de indivíduos podem vir a ocupar" (FOUCAULT, 2009, p.279-280).

Tentei essa distinção com um único fim: mostrar que essa função-autor, já complexa quando se tenta localizá-la no nível de um livro ou de uma série de textos que trazem uma assinatura definida, comporta também novas determinações, quando se tenta analisá-la em conjuntos mais amplos - grupos de obras, disciplinas inteiras (FOUCAULT, 2009, p.286).

E aqui retomo a pista deixada por Basbaum (1996), sobre a sequencialidade das obras, que diz respeito à diferença entre analisar uma peça isolada e observar conjuntos inteiros. $O$ próprio Foucault é exemplo dessa distinção, já que a sua obra é o produto e a produção de uma existência, e seus textos ganham outros sentidos quando vistos como partes de um todo (FARINA, 1999).

Seus objetos de filosofia (...) não se deram como manifestações de genialidade avulsos, mas na processualidade das encarnações afetivas, tornando-se condutores de passagem de vida. A obra é mais que a peça e, no entanto, se faz na peça. A obra são os ensaios da vida. É a experimentação (FARINA, 1999, p.52; grifo nosso).

A partir das funções-autor expostas por Foucault e Barthes, começo a esboçar uma noção do que pode propor, indiretamente, o autor em uma sociedade: desconstruir discursos, subvertê-los; cruzar saberes de diferentes contextos e ressignificá-los. "Trata-se, em suma, de retirar do sujeito (ou do seu substituto) seu papel de fundamento originário, e de analisá-lo como uma função variável e complexa do discurso" (FOUCAULT, 2009, p.287). Reafirmo aqui a figura do autor 
como um mediador de sentido, um operador que emerge das relações variáveis entre texto, contexto e leitor.

\section{AUTORIA NO CAMPO DO DESIGN}

Transpondo para o campo do design, é possível enxergar variáveis paralelas a estas, nas múltiplas relações possíveis entre as pessoas e os artefatos em determinado contexto sócio-cultural. Enquanto o lugar do autor na literatura era tão legitimado que precisava ser deposto (BARTHES, 2004) ou, no mínimo, ter as suas funções revisadas, em favor das questões presentificadas por Foucault (2009), no design ele nem sequer havia encontrado lugar de legitimação. Visto que a discussão sobre design autoral começou a ter representação apenas em meados dos anos noventa.

Na superfície, ao menos, pareceria que os designers estariam se afastando dos textos científicos, anônimos - nos quais princípios visuais invioláveis foram revelados através de pesquisas visuais extensivas - em direção à posição na qual o designer poderia assumir algum nível de propriedade da mensagem (e isso em um tempo em que a teoria literária estava se afastando dessa posição). Mas alguns dos atributos institucionais da prática do design eram contrários às tentativas entusiásticas de auto expressão. A ideia de uma mensagem descentrada não necessariamente se ajusta a uma relação profissional na qual o cliente está pagando para o designer comunicar informações ou emoções específicas (ROCK, 1996; tradução nossa).

Na década de noventa constituiu-se um intenso debate que se estende até o presente e parece ter fôlego ainda para muitos desdobramentos. Artigos, exposições e projetos dessa época deram visibilidade para a discussão, colocando o designer como figura central no processo de comunicação visual, contestando as ideias de neutralidade e pura objetividade, herdadas do formalismo. "Designers como autores buscam um reforço do significado em seus projetos" (MCCARTHY, 2013, p.12). Mas este ponto de vista é alvo de crítica dentro e fora do campo, já que a ideia de autoria pode levar a uma 
armadilha de ego, uma busca vaidosa dos designers autores por reconhecimento, ao se envolverem com o conteúdo, fazendo-os esquecerem seus lugares de origem que, segundo o conhecimento tradicional da profissão, seria focado na forma visual (MCCARTHY, 2013).

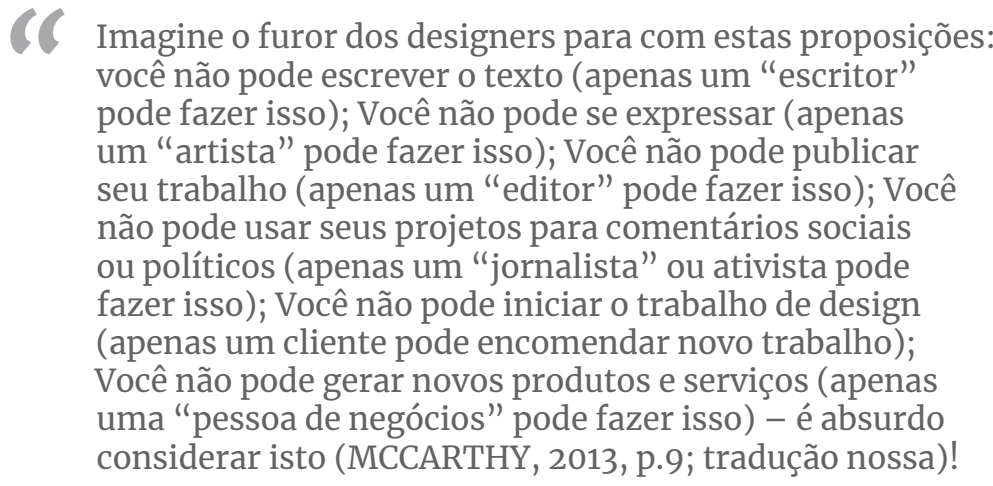

Esse parágrafo foi colocado por Steve McCarthy como uma provocação introdutória acerca da pluralidade de funções vetadas, ignoradas, debatidas e questionadas sobre o design autoral em seu livro The Designer as...: Author, Producer, Activist, Entrepeneur, Curator, and Collaborator: New Models for Communicating. Era absurdo, também para mim, considerar tais negações. O que eu entendia por design autoral era justamente a possibilidade de um fazer design menos sujeitado às práticas mercadológicas convencionais e mais abrangente, envolvendo-se tanto com a forma quanto com o conteúdo. E foi este desejo de imprimir algo de singular nas atividades de design que experimentava, inclusive as que estavam diretamente ligadas ao mercado, que me motivou a pesquisar os processos de criação. Seja da criação/proposição em relação ao seu autor, seja do autor em relação à criação. Então, para ajudar a recortar, comecemos pelo que não é design autoral.

Não é um estilo (grunge é um estilo). Não é um meio (a impressão é um meio). Não é uma técnica (a caligrafia requer técnica). Não é uma especialização (o design de embalagem é uma especialização). Não é um gênero (a montagem fotográfica é um gênero). 
Não é um movimento (o modernismo suíço é um movimento). Não é uma filosofia (a fenomenologia é uma filosofia) (MCCARTHY, 2013, p.11; tradução nossa).

Os assuntos abordados, as formas de abordagem, os meios utilizados e as intenções, chamadas autorais, podem ser muitas e muito diferentes entre si. Enquanto alguns designers iniciam seus próprios trabalhos, outros vinculam-se a formas de colaboração com profissionais de outros campos. Como, por exemplo, "músicos, engenheiros de software, atores, cientistas, arquitetos, artistas e outros. Frequentemente, designers integram escrita, edição, design e publicação em um plano que reforce/aprofunde suas mensagens" (MCCARTHY, 2013, p.11; tradução nossa).

\footnotetext{
CC Pode ser que o real desafio seja abraçar a multiplicidade de métodos - artístico e comercial, individual e colaborativo - que compreende a linguagem do design. Um exame do designer-enquanto-autor pode nos ajudar a repensar o processo, expandir métodos de design e elaborar nossa perspectiva histórica para incorporar todas as formas de discurso gráfico. Mas enquanto as teorias de autoria gráfica podem mudar o modo como o trabalho é feito, a preocupação principal tanto do espectador quanto do crítico não é quem fez, mas o que fez e como o fez (ROCK, 1996; tradução e grifo nossos).
}

A questão da autoria no design, da maneira que a venho conduzindo, anda por entre os extremos. Se, por um lado, não cultivo a ideia de legitimação de poder e autonomia total do discurso como auto expressão, por outro, tampouco me contenta esse envolvimento apenas na dimensão formal e, necessariamente, subordinado às lógicas de mercado dominantes.

Por ora, delineio autoria no design como um modo de estar, um senso de responsabilidade com ambos, conteúdo e forma, que vai constituindo, ao longo da trajetória (vida), uma ética própria. Este modo de estar, que se reinventa e se revisa a cada passo, se aproxima da ideia de estética da existência em Foucault (1995, apud FARINA, 1999), e não só de uma estética visual/formal, como pode sugerir uma assina- 
tura de estilo, por exemplo. São as escolhas que constituem uma ética. "Trata-se da vida tornada matéria expressiva na criação de uma estética da existência. Essa matéria modulante é com a qual se age, com a qual se interatua política e eticamente na produção estética" (FARINA, 1999, p.53).

\footnotetext{
CC Além de usar imagem e texto, tanto em forma quanto em conteúdo para comunicar, designer-autores têm o poder de iniciar. Enquanto a maioria dos trabalhos de design gráfico continua a ser encomendada dentro do típico modelo de serviço cliente-designer-mercado, designers como autores produzem conteúdo original e dão-lhe a forma apropriada. O design autoral pode ser autoiniciado, sem um cliente convencional, mas isso não significa que ele não tem um público. Em vez de ser reativo, é pró-ativo (MCCARTHY, 2013, p.95; tradução nossa).
}

Eu acrescento ainda que, mesmo em trabalhos encomendados por clientes e/ou desenvolvidos dentro de um ambiente mercadológico, como as agências de comunicação e estúdios de design, seria possível em algum nível, manter esse senso de responsabilidade, oferecendo um ponto de vista consistente para o projeto, seja ele de interesse pessoal, ou não.

É justamente por seu caráter de prática mediadora, que o design oferece a possibilidade de relacionar saberes de diferentes naturezas, fazer conexões entre elementos e criar formas de expressão a diferentes formas de conteúdo. E, nesse sentido, o movimento de alternância entre projetos motivados por aspirações pessoais e os trabalhos ditos convencionais, pode contribuir para a potencialização de ambos.

Se descartamos o trabalho convencional, estamos descartando o caráter fundamental do projeto como uma prática mediadora, um frame, um intermediário. A maioria dos projetos é colaborativo, não o trabalho de um único autor. A maioria dos projetos tem muitos autores - entre eles o cliente. Todos nós fazemos trabalhos que sinalizam nossos valores e aspirações mais queridos, mas nossos "trabalhos diurnos" nos ajudam a tatear o caminho ao qual essa prática diz respeito. Insistir em que cada parte do trabalho de um designer deve se encaixar em um único molde ou padrão não se encaixa com o caráter fundamental do design como uma 
ferramenta para fazer coisas e como uma membrana entre forma e conteúdo (LUPTON ${ }^{[6]}, 2013$, p.49).

Um exemplo de designer que conquistou reconhecimento como designer-autora é o de Paula Scher ${ }^{[7]}$ que, ao longo de sua trajetória, vem transitando por muitos espaços. Mesmo variando as funções, os meios, as técnicas, os públicos e as modalidades de projetos com os quais se envolve, alguns traços parecem se manter. A paixão pela experimentação tipográfica, a reinvenção de si e dos estilos que propõe vem compondo isso que, acredito, ser da ordem da ética. Em um TED Talks ${ }^{[8]}$, a fala um pouco dos princípios que a acompanham.

Meu trabalho é um jogo. E eu brinco quando projeto. Eu até olhei no dicionário, para ter certeza que eu realmente faço isso, e a definição de jogo era, número um: envolverse em uma atividade ou empreendimento infantil; e número dois: apostar. E eu percebo que faço as duas coisas quando estou fazendo design. Eu sou uma criança e estou apostando o tempo todo. E penso que se você não é/não está, provavelmente há alguma coisa essencialmente errada com a estrutura ou a situação em que você se encontra, se você é um designer (SCHER, 2008; transcrição e tradução nossas).

Cito-a como exemplo de uma designer autora, não só por uma assinatura de estilo, que em alguma medida aparece em seus trabalhos, mas também, e principalmente, por essa postura de experimentar com os projetos, de se colocar neles e se transformar com eles. O que ela atribui à sua prática é mais que um estilo visual unificado, até mesmo porque ela vem criando peças e se envolvendo em projetos heterogêneos ao longo da sua carreira no design. Mas o que parece permanecer é o critério que a acompanha. Um critério a respeito da seriedade, que difere da solenidade, dito por ela mesma:
[6] Entrevistada concedida a Steve Mccarthy, 2013

[7] Paula Scher começou sua carreira criando capas de álbuns para CBS e Atlântic Records. Formou sua própria empresa de design, e depois de alguns anos se juntou à Pentagram. Durante sua carreira, ela criou trabalhos para clientes como Citi Bank, Metropolitan Opera, o Museu de Arte Moderna e a Filarmônica de Nova York, entre outros. Fonte: Design Is History, 2017.

[8] Paula Scher fala sério. Fonte: Ted Talks, 2018.

Agora, quando eu aplico a definição de Russel Baker sobre solenidade ou seriedade ao design, isso não necessariamente prova qualquer coisa no que diz respeito a qualidade. $O$ design solene é geralmente importante e muito eficaz. É também socialmente correto, e é aceito por públicos apropriados. É aquilo pelo qual estão lutando 
os designers corretos e todos os clientes. O design sério, a brincadeira séria, é outra coisa. Primeiro, geralmente acontece espontaneamente, intuitivamente, acidentalmente ou incidentalmente. Pode ser atingido através da inocência, ou da arrogância, ou do egoísmo, às vezes da falta de cuidado. Mas na maioria dos casos, é atingido através de todas as partes meio loucas do comportamento humano que realmente não fazem nenhum sentido. 0 design sério é imperfeito. É recheado com o tipo de leis do oculto que se originam de algo que é o primeiro do seu tipo. $O$ design sério é também - muitas vezes - bastante mal sucedido do ponto de vista solene. Isto porque a arte da brincadeira séria tem a ver com invenção, mudança, rebelião - e não com perfeição. A perfeição acontece durante brincadeiras solenes (SCHER, 2008; transcrição e tradução nossas).

A seriedade de que fala Paula Scher, está para mim como possibilidade de mudar o foco de atenção. Uma ligeira mudança na lógica do pensamento que, acredito, seria capaz de produzir muitas diferenças. Ao invés de repetir exaustivamente uma única forma de fazer design ao longo de uma existência, buscando atingir a perfeição, ou desvendar fórmulas visuais invioláveis e pré-existentes, a exemplo do grid de Müller-Brockmann (ROCK, 1996), estaríamos disponíveis a experimentar com mais e outras formas de saber. Colocar matérias do design e matérias de vida para jogar, e estarmos disponíveis para ir com elas até onde nos levarem.

É aí que se mostram insuficientes as classificações, já que a autoria perceptível em seu trabalho não é tangível e descritível, não se encerra em um único modo de fazer, tampouco significa a ausência de vínculo comercial. Paula Scher parece misturar sensibilidade e técnica entre as experimentações de motivação pessoal e os trabalhos encomendados por clientes. O que observo disso é o quanto essa maneira de estar, nas práticas de design, abre de espaços de atuação. Ainda mais em colaborações com outros campos.

É fato que, enquanto designers, precisamos lidar com os interesses do mercado, igualmente, dependemos desse tipo de reconhecimento para a manutenção de algum respaldo. $E$, mesmo para favorecer microformas singulares (vitais) de subverter essa lógica, é preciso negociar com ela. 
Vivemos em um mundo no qual a autoridade está cada vez mais dispersa em várias entidades corporativas que escondem seu funcionamento interior do olhar do público. Ao se comprometerem com formas complexas de invenção literária e gráfica, autores individuais (que supostamente são os problemáticos "pontos de origem únicos") incentivam os leitores a explorar, experimentar e questionar o mundo de formas ricas, abertas e, em última análise, fortalecedoras (POYNOR, 2010, p.72).

(...) o mercado hoje converteu-se no principal - senão único - dispositivo de reconhecimento social. As subjetividades tendem a orientar-se cada vez mais em função deste reconhecimento e, portanto, das formas que se supõe valorizáveis, e cada vez menos em função da eficácia das formas enquanto veículos para as diferenças que se apresentam. Na constituição deste modo menos experimental e mais mercadológico de subjetivação, participam especialmente os monopólios da mídia. Em suas artérias eletrônicas, navegam por todo o planeta imagens de formas de existência glamourizadas, que parecem pairar inabaláveis sobre as turbulências do vivo. A sedução destas figuras mobiliza uma busca frenética de identificação, sempre fracassada e recomeçada, já que se trata de montagens imaginárias (ROLNIK, 1996, p.2-3).

Das palavras de Poynor e Rolnik, faço uma leitura sobre o senso de responsabilidade da autoria: preservar o inegociável nas negociações que precisa estabelecer com o mercado. O inegociável é o conjunto de critérios éticos de que se é portador. O inegociável aparece quando revisamos nossas perguntas mais profundas. Por exemplo: com que pares escolho me aliar? Para quais estruturas meu trabalho contribui? Que tipo de cadeia econômica eu favoreço com minhas criações? Revisar e preservar o inegociável desde a pulsão criadora até o momento em que se inscreve na realidade como matéria expressiva, é o que atribuo à função do autor no interior das sociedades.

\section{CONSIDERAÇÕES FINAIS}

Nesse momento já reúno algumas pistas do que seria esse gesto do autor: um mediador de sentido; uma entidade an- 
tropofágica que se alimenta de múltiplos discursos, múltiplas referências - não só estilísticas - e deixa que tais influências o atravessem [o autor] modificando-o e sendo modificadas por ele. "A voz do autor se cala, para que se faça palavra e forma aquilo que é antes disto. Não um universal a ser proclamado, mas um universo a ser inventado. Não é o autor quem fala, mas, tampouco ele emudece" (FARINA, 1999, p.54).

Ao longo desta escrita, a questão da autoria foi sendo colocada sob uma perspectiva ética e estética, em que o gesto do autor pode produzir efeitos no leitor e, também sobre si. Para além da ideia de criação autocentrada ou autoexpressiva e que, ao produzir diferenciação, incide no funcionamento coletivo de uma sociedade.

\section{REFERÊNCIAS}

BASBAUM, Ricardo. Performance: a questão da autoria.

Performáticos, Performance e Sociedade. Brasília,

Editora Universidade de Brasília, 1996, pp. 47-51

BARTHES, R. A morte do autor. O Rumor da

Língua. São Paulo: Martins Fontes, 2004.

SCHER, Paula. Paula Scher. Disponível

em: <http://www.designishistory.com/1980/

paula-scher/> Acesso em: 27 mar 2017.

FARINA, Cynthia. Vida como obra de arte, arte como obra de vida: por uma pedagogia das afecções. Universidade Federal de Pelotas. Dissertação de Mestrado, 1999.

FOUCAULT, Michel. Estética: literatura e pintura, música e cinema. Ditos \& Escritos III. Trad. Inês Autran Dourado Barbosa - 2.ed - Rio de Janeiro. Forense Universitária, 2009.

LUPTON, Ellen (org.). Intuição, ação, criação.

São Paulo: Gustavo Gili, 2013 
LUPTON, Ellen. The Designer as Producer. In: The

Education of a Graphic Designer. New York: Allworth

Press, 1998. Disponível em: < http://elupton.com/2010/10/

the-designer-as-producer/>. Acesso: em 07/04/17.

MCCARTHY, Steven. The Designer As...: Author,

Producer, Activist, Entrepeneur, Curator, and

Collaborator: New Models for Communicating.

Amsterdan: BIS Publishers, 2013.

MEGGS, Philip B. História do design gráfico.

São Paulo: Cosac \& Naify, 2009.

POYNOR, Rick. Abaixo as Regras: Design

Gráfico e Pós Modernismo. $1^{\text {a }}$ Ed. Porto Alegre:

Bookman Companhia Editora, 2010.

ROCK, Michael. The designer as author. Eye Magazine.

1996. Disponível em: <http://www.eyemagazine.com/feature/

article/the-designer-as-author> Acesso em: 10 ago. 2016.

ROLNIK, Suely. Arte Cura: O híbrido de Lygia

Clark. São Paulo, 1996. Disponível em: <http://

www.pucsp.br/nucleodesubjetividade/Textos/

SUELY/Hibrido.pdf>. Acesso: em 07 abr. 2017.

SCHER, Paula. Paula Scher fala sério. Tedtalks. 2008.

Disponível em: <https://www.ted.com/talks/paula_scher_ gets_serious?language=pt-br>. Acesso em: 27 mar. 2017. 